\title{
Portotrack Project : Communication Interface - Vehicle to Port INFRASTRUCTURE - PORTOLOG
}

\author{
Luciano Breve Abrahao ${ }^{1}$, Bruno Scarano Paterlini ${ }^{2}$, Erico de Araújo Fernandes ${ }^{3}$, \\ Leopoldo Yoshida ${ }^{4}$, Armando Laganá ${ }^{5}$ \\ ${ }^{1}$ Mercedes-Benz do Brasil, USP \\ ${ }^{2}$ Mercedes-Benz do Brasil, USP \\ ${ }^{3}$ Mercedes-Benz do Brasil, FEI \\ ${ }^{4}$ USP \\ ${ }^{5}$ USP \\ E-mails: luciano.abrahao@daimler.com,bruno.paterlini@daimler.com, \\ erico_araujo.fernandes@,daimler.com, leopoldo.yoshioka@usp.br, lagana@1si.usp.br
}

\begin{abstract}
Maritime means of transportation is extremely important in the import and export processes in Brazil due to its large coastal extension. Besides that the port logistics operation is quite complex and contains several challenges. At times, Brazil has a very poor railway system and it is necessary to transport the great majority of cargoes by trucks. Thus such an intense flow of trucks makes this scenario even more complex. Since 2012, several actions have been started to improve the trucks cargo logistics, among them a scheduling system, use of regulatory yards, RFID identification technologies, among others. A project so-called 'Cadeia Logística Portuária Inteligente (Portolog)' aims to effectively integrate cargo control from loading to its final destination. Part of its features was initially applied at Santos Port, near to São Paulo city. This article proposes a communication interface model that will allow the fleet and terminal operators to have a clear, qualitative and real-time view on the truck's displacement. The emphasis is to integrate vehicle diagnostics as additional information for better cargo arrival estimation. Key words: Portolog, SGTC, Port Logistics.
\end{abstract}

Key words: Portolog, SGTC, Port Logistics.

\section{INTRODUCTION}

Brazil has 8,500 kilometers of navigable coasts that makes the sea environment very attractive for cargo transportation. From 34 public ports, 16 are delegated to states or municipalities, and 18 seafarers are directly managed by Doca Companies, mixed capital companies, which have as majority shareholder the Federal Government and, therefore, they are directly linked to the Ports Department.

There are seven companies responsible for the country's ports, and among them is the Doca Company of the State of São Paulo (CODESP), which manages the Santos port [1].

If we consider the number of containers handled between the different ports of the country in 2016 we reach almost 2,400,000 units, as shown in figure 1. Only the port of Santos handled 
approximately 960,000 containers. Trucks are the responsible to transport these containers over the land. Each truck has capacity to transport between 1 or at most 2 containers, that leads to a number of 800 thousand trucks routes. In fact it means a high complex logistics scenario so-called port logistics.

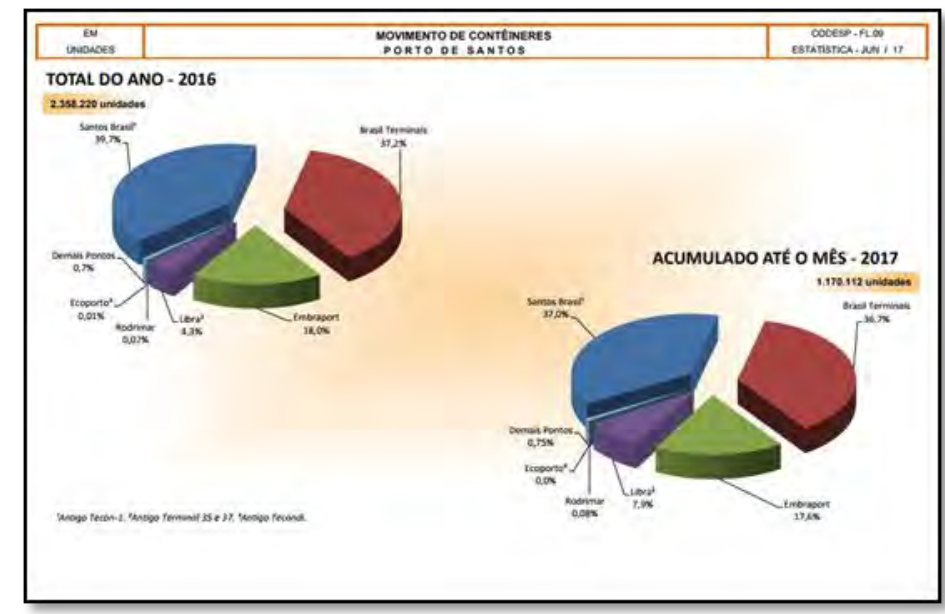

Figure 1. Statistical data on the movement of container ports.

Since 2012, a working group was formed by the Ministries of Transport and Agriculture and the Special Secretariat of Ports, National Water Transport Agency (Antaq), National Transportation Agency (ANTT), CoODESP among others. This group is studying short, medium and long term ways to significantly improve the agricultural production outlet logistics in order to alleviate the trucks traffic jams that occur mainly during the harvests [3].

\section{TRUCK TRAFFIC MANAGEMENT SYSTEM (SGTC)}

The first access control system through prior scheduling began on January 1, 2014, pursuant to Resolution DP No. 47.2013 23 ${ }^{\text {rd }}$ of April, 2013. Since then CODESP has defined for each terminal from Santos Port the maximum trucks capacity by time, according to their operational capacity, as well as a maximum capacity of internal parking usage $[4,5]$.

Trucks used for grain transportation purposes still require a step beyond scheduling. They are required to a pass through a Regulated Yard accredited to the Port Authority before moving to the port terminals. Unscheduled trucks arriving at this regulated yards will be not allowed to go.

The scheduling timeframe was defined with a fixed and continuous period of 06 (six) hours, starting at a scheduled time through the system called SGTC (Cargo Terminal Management System). Scheduled trucks arriving at Regulatory Yard at a later time than defined in the scheduling window are treated as unscheduled. They have to be rescheduled by Port Terminals. In this case, applicable penalties defined by Antaq may be imposed through Resolution No. 3,274, published on February $7^{\text {th }}, 2014$ in the Federal Official Gazette: fine for the terminal between R $\$ 1$ thousand and R\$ 2 thousand per vehicle in an irregular situation and from $R \$ 10$ thousand to $R \$ 20$ thousand per vehicle that interrupts port traffic.

The tolerance of early reception of the trucks by the Regulating Yards was defined in up to 5 (five) hours, in relation to the time scheduled in the SGTC. 
The Port Terminals must inform CODESP the truck data scheduling between 12 hours to 7 days prior to the receipt of the trucks, in accordance with the quotas defined.

Contingency situations were also defined, which, based on their finding by CODESP, allow reprogramming by terminals or their agents [4]. These situations are:

a. The Interruption, of electricity supply or other public services, as well as other situations of unforeseeable circumstances and force majeure that prevent or impair the physical operation and operation of port control systems;

b. Traffic congestion and other land access problems caused by rain, falling barriers, construction works, accidents or other causes within a perimeter of up to $500 \mathrm{~km}$ of access roads to the port, duly confirmed by the Federal Highway Police or Defense Bodies Civil, when applicable;

c. Delays or unfeasibility of transshipment due to faults in port equipment and problems in maritime access due to poor weather conditions, dredging, delays in ship loading or contingencies arising from the services of pilotage, among others. [4].

In a report published in 2014 the Cubatão Yard administration reported that in the first few months after the implementation of the SGTC the wait to unload that reached 4 days. After some months this value reduced to a value between 14 and 18 hours [6]. In the 2014 harvest plan, it was announced that the logistics improvement brought an average decrease of $7 \%$ in freight value. [7]. Figures 2 and 3 illustrate the scheduling page of the SGTC system.

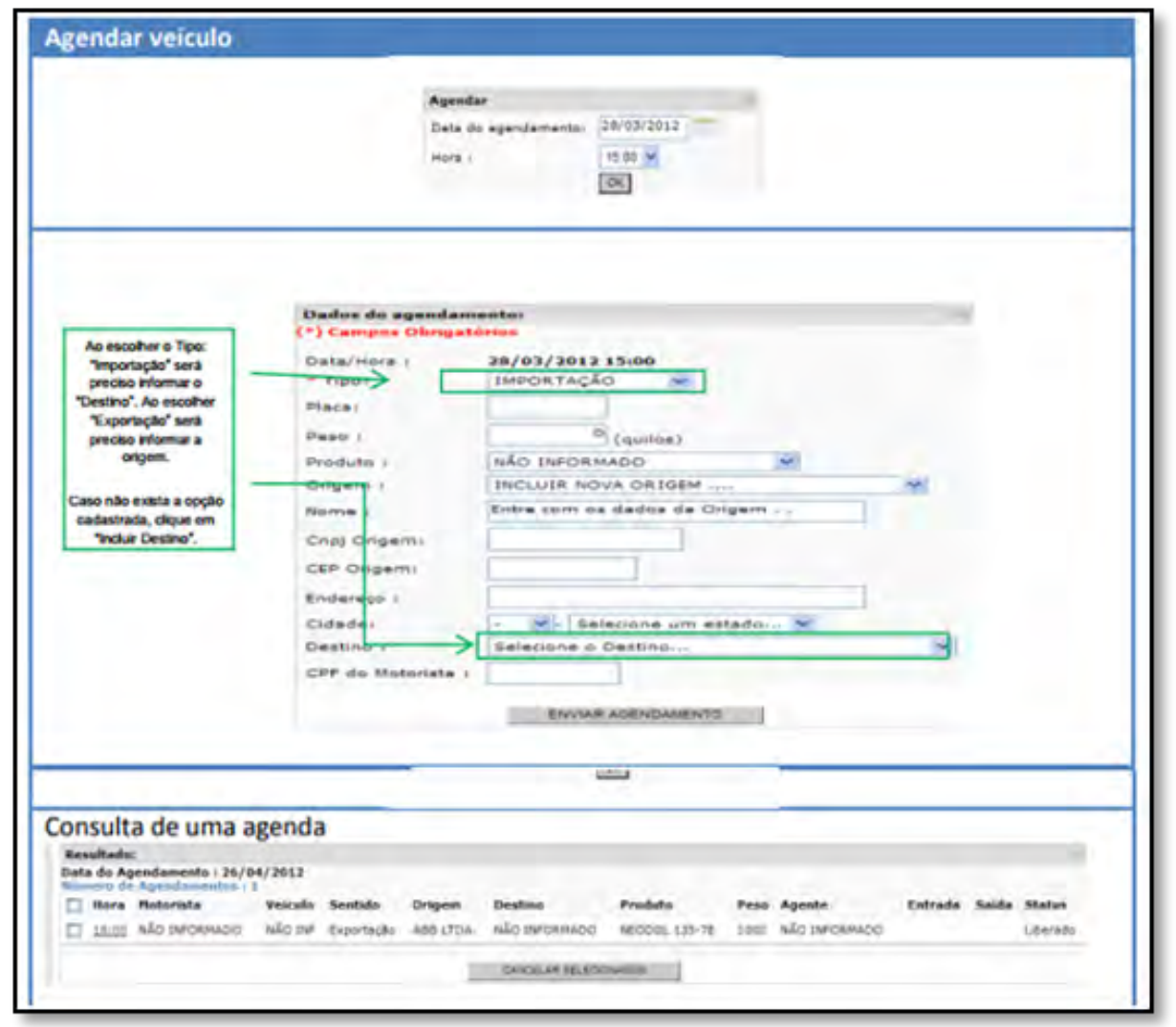

Figure 2. Scheduling system SGTC [8]. 


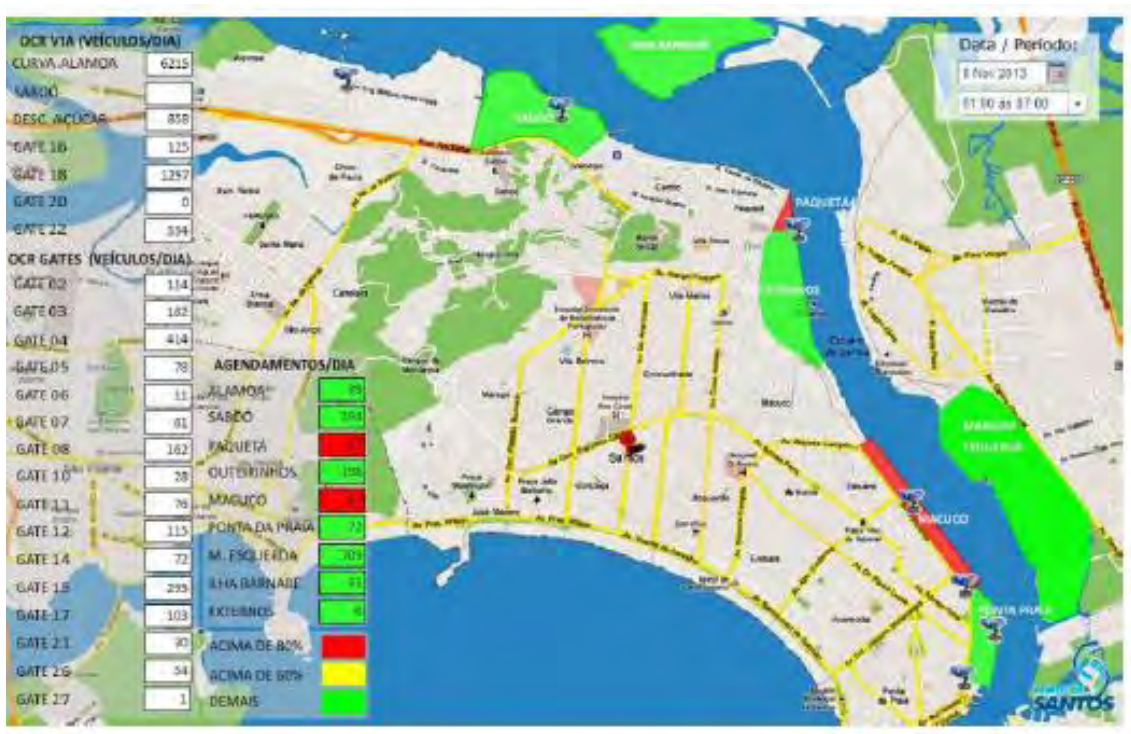

Figure 3. Monitoring Panel SGTC [8]

\section{PORTOLOG PROJECT}

Portolog Project (Intelligent Port Logistic Chain) was created to gradually replace the SGTC with the main objective of integrating the whole load cycle into a system. The system aims to synchronize the arrival dates of ships and cargo at the terminals, the scheduling and accreditation of trucks to use port full capacity. After login the system, Portolog starts to monitor its trip to the port, through electronic monitoring. Trucks are identified with smart tags, which send data through communication systems. It allows to track and managing transportation more efficiently. The logistics process should gain more security, agility and expressive performance indexes $[9,10]$.

Through expediting letter No. 37 from $27^{\text {th }}$ of June, 2014, it was established that terminals were required to interconnect their logistics systems for scheduling the receipt of trucks and cargoes to the Portolog system. The system will be implemented in all the ports of the country but had first test at Santo Port. The transition phase between the systems at Santoa Port Santos occurred as shown in figure 4 .

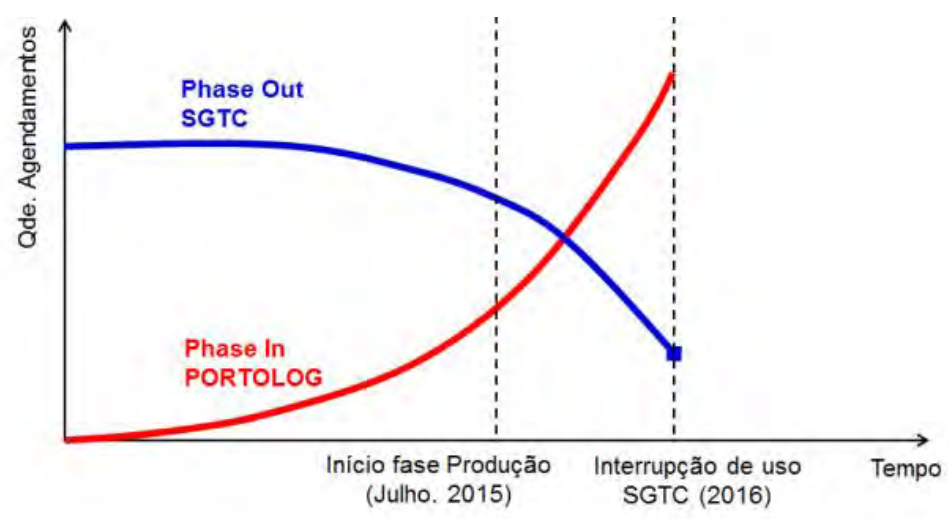

Figure 4. Transition phase: SGTC to Portolog [5].

Before arriving at the port, the trucks will be directed to a first yard located nearby to Santos. They will be retained in the yards to be registered / scheduled in the Portolog system. After analysis of availability, the scheduled trucks are sent to the second yard close to the port. 
They will be received and informed the departure timeto go to the port terminals, as shown in figure 5. [6]

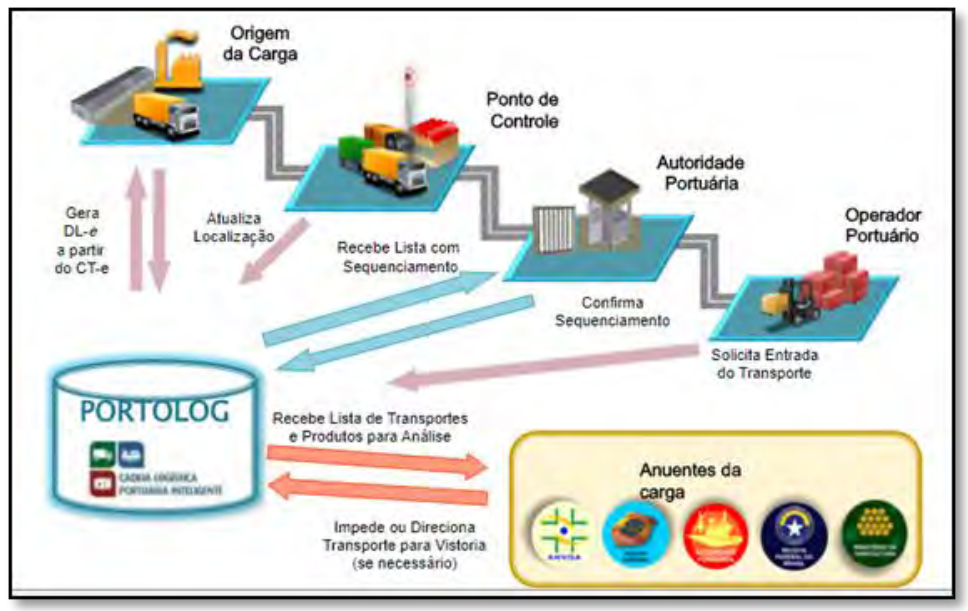

Figura 5. Overview Logistic chain Portolog [5].

The intention is to transfer the traffic jams formed along the road, without infrastructure, to a safe place with infrastructure. Portolog has the function of providing a specially developed tool for integrated monitoring and efficient load control. The new system will also be linked to the Paperless Port (an information system that brings together in a single management medium the information and documentation of the goods shipped and landed in the ports) and the VTMIS Traffic Monitoring System. It will enable the monitoring and management, in real time, the flow of veels in the navigation areas [5].

The registered trucks will receive an RFID (Radio Frequency Identification) tag and will be identified automatically before entering the port. Figure 6 illustrates the registration system and vehicle identification.

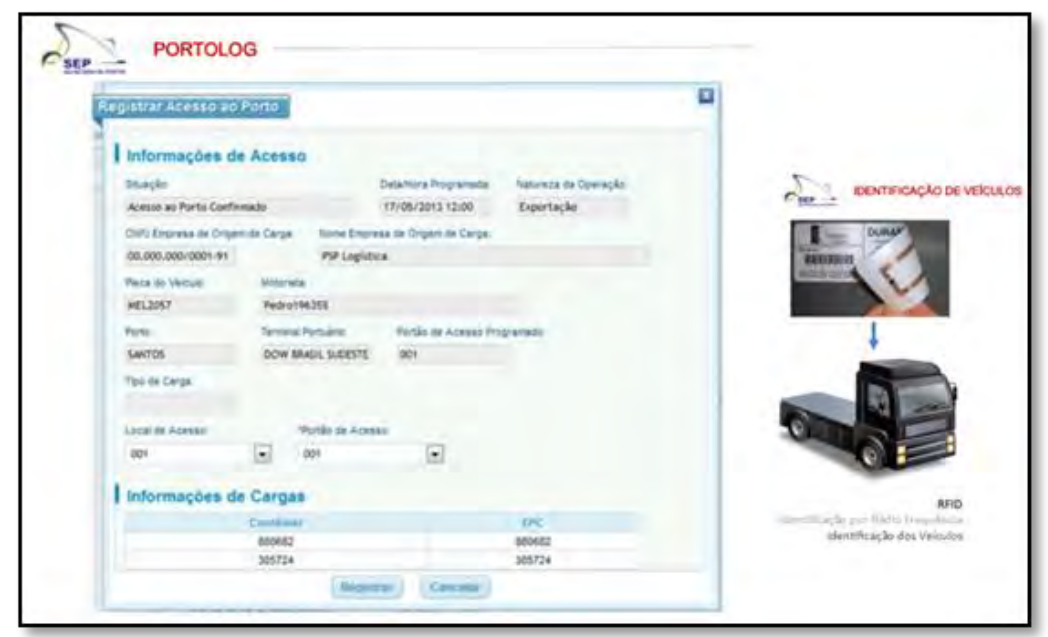

Figura 6. PortoLog Project $[9,11]$.

This project is being applied by steps and it is currently with the optimized scheduling step already in operation at Santos Port. The purchase of equipment for trucks and cargo identification via RFID is in the execution phase. The regulatory yards are under study as well as the trucks tracking since load origin [11]. 


\section{FMS (Fleet Management System)}

In order to have these systems more closely integrated with vehicle data, fleet management equipment can be used. They would be based on the standard data interface for commercial vehicles called FMS (Fleet Magament System). The development of this standard comes as the responsibility of the European Association of Automotive Manufacturers (ACEA) in cooperation between manufacturers Daimler AG, MAN AG, Scania, Volvo, DAF Trucks and Iveco, as shown in figure. Its first versions was published in 2002 , underwent two subsequent reviews until the publication of the new Remote FMS standard (rFMS) in 2014. rFMS has the advantage of having a dedicated cloud infrastructure[12].

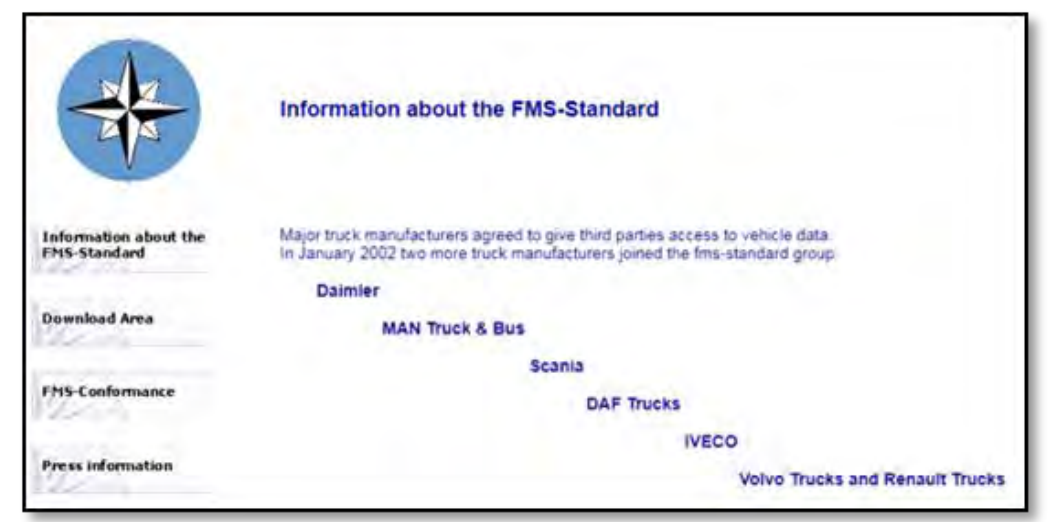

Figure 7. Commercial vehicles manufacturers supporting the FMS standard[12].

The data is encoded according to SAE CAN J1939 standard and allows you to extract information such as fuel level and fuel consumption, speed, use of the clutch, engine hours among others. These processed data can provide information on the quality of driving, allowing the determination of inappropriate driving events (sudden braking, acceleration, improper gear changes, excessive fuel consumption, among others). This makes possible the generation of real-time alarms, as well as highlighting the need for retraining of drivers who present with an inappropriate driving profile.

\section{PROPOSED PROJECT: PORTOTRACK}

Real-time load-displacement information demands the application of an additional layer of information that comes from trackers that equip the trucks. This layer of the system must have a well-defined protocol that enables all vehicle assemblers to develop compatible equipment or even prepare the vehicular infrastructure to receive external equipment.

The proposed model, called Portotrack, proposes two phases of implementation of a two-way communication transmission of relevant information from the truck to the port and fleet operators, as well as the reverse path. The proposal should be implemented in two stages in order to allow implementation in the short term:

\section{Portotrack Phase 1 - Implementation for the current fleet of trucks:}

To use tracking equipment compatible with FMS 1.0 (Fleetmanagement System). Access to data on the server should be done through a Simple Object Access Protocol (SOAP). This interface is a protocol for structured information exchange in a decentralized and distributed 
platform, a concept widely diffused among technology companies that deal with systems vehicle tracking. Figure 10 schematically illustrates this proposal.

\section{Portotrack Phase 2 - Implementation for future fleets:}

a. For these fleets it should be mandatory to contain equipment compatible with the rFMS standard: it eliminates the need for cloud infrastructure shown in figure 1, since the cloud is already part of the infrastructure created for the rFMS. So the information can be searched directly in this base. In addition, rFMS already has standard updates that have been introduced since version 3.0, which makes it mandatory for automakers to provide information from vehicle diagnostics and trailer. Diagnosis specifically contains information of great relevance. It gives information about vehicle technical condition and allows to visualize situations of break don that can delay its unload.

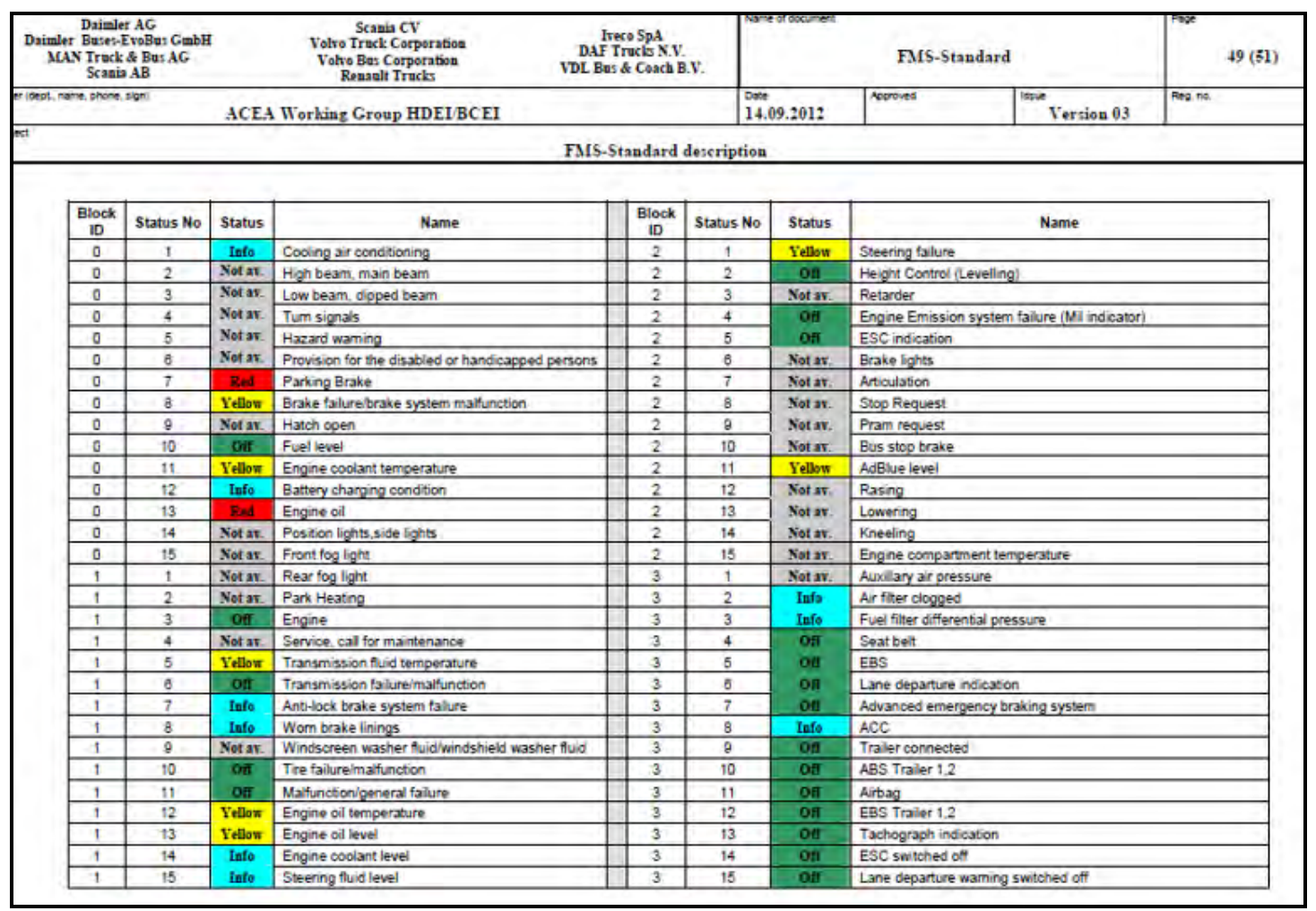

Figure 8. Diagnose over FMS standard supported on version 3.0 [12].

b. Truck should be equipped with sensors that provide axle load information and send the information according to the rFMS standard, as shown in Figure 9. 


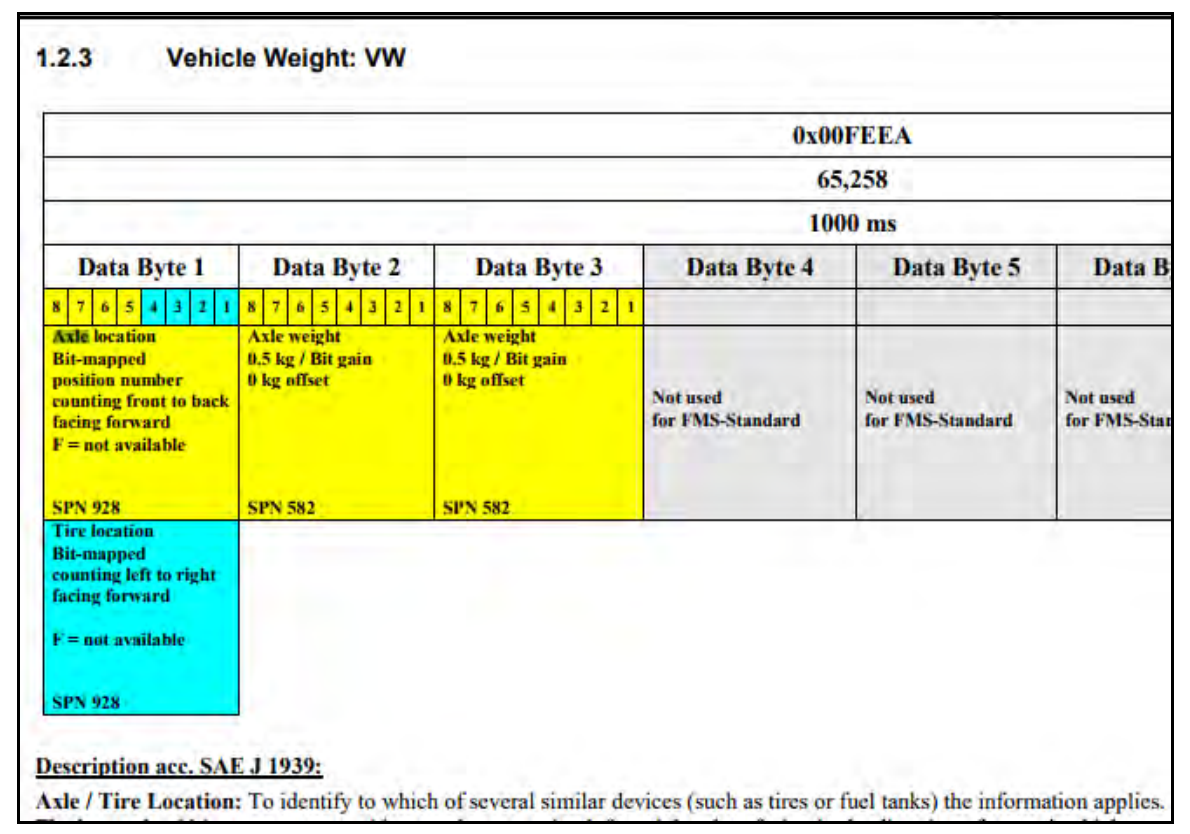

Figure 9. Description on axels load supported on FMS Standard version 3.0 [12].

Additionally the rFMS is described in phase 2 because although it defined standardization the release is still in place in Europe.

Figures 10 and 11 illustrate the scenarios.

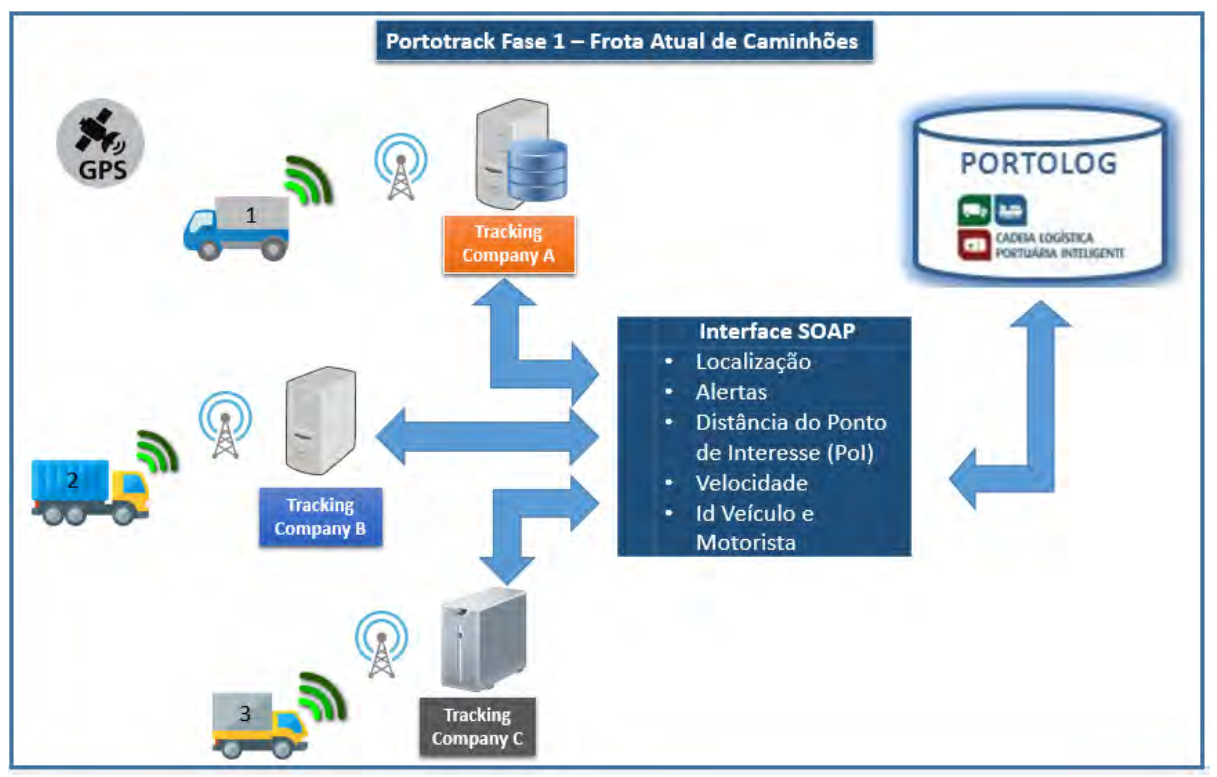

Figure 10. Portotrack project phase 1. 


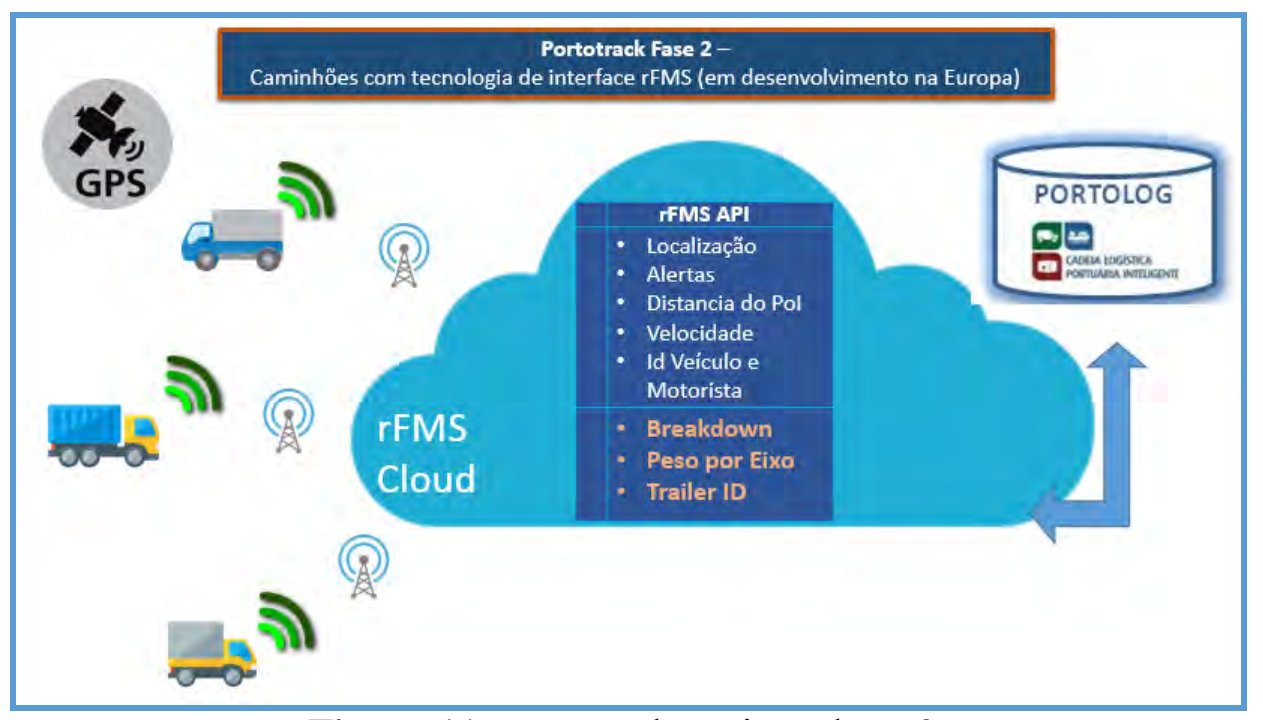

Figure 11. Portotrack Project phase 2.

The table 1 shows the comparison between the current scenario and the gains from the implementation of the Portotrack project.

Table 1 . Comparison between the current scenario and the scenario with PortoTrack.

\begin{tabular}{|c|c|c|}
\hline Current scenario & $\begin{array}{c}\text { Scnenario with } \\
\text { Portotrack Fase } 1\end{array}$ & $\begin{array}{c}\text { Scenario with } \\
\text { Portotrack Fase } 2\end{array}$ \\
\hline $\begin{array}{l}\text { Portolog in early implementation. } \\
\text { Scheduling of deliveries in } \\
\text { operation but no information on } \\
\text { real-time truck moving. }\end{array}$ & $\begin{array}{l}\text { Tracking equipment on } \\
\text { Trucks complying with the } \\
\text { FMS } 1.0 \text { Standard. }\end{array}$ & $\begin{array}{l}\text { Tracking equipment on } \\
\text { trucks conforming to the } \\
\text { rFMS Standard. }\end{array}$ \\
\hline - & $\begin{array}{l}\text { Equipment with Gaging } \\
\text { information with forecast of } \\
\text { arrival time. }\end{array}$ & $\begin{array}{lr}\text { Equipamentos } & \text { com } \\
\text { Informação } & \text { de } \\
\text { geoposicionamento } & \text { com } \\
\text { previsão de horário de } \\
\text { chegada }\end{array}$ \\
\hline- & - & $\begin{array}{l}\text { Informação de diagnose } \\
\text { veicular com informação de } \\
\text { potenciais atrados }\end{array}$ \\
\hline- & $\begin{array}{l}\text { Information: } \\
\text { - Location; } \\
\text { - Alerts; } \\
\text { - Distance of Point of } \\
\text { Interest (PoI); } \\
\text { - Velocity; } \\
\text { - Identification of the vehicle } \\
\text { and Driver. }\end{array}$ & $\begin{array}{l}\text { Information: } \\
\text { - Location; } \\
\text { - Alerts; } \\
\text { - Distance of Point of Interest } \\
\text { (PoI); } \\
\text { - Velocity; } \\
\text { - Identification of the vehicle } \\
\text { and driver. } \\
\text { - Breakdown; } \\
\text { - Weight per axle; } \\
\text { - Trailer ID. } \\
\end{array}$ \\
\hline
\end{tabular}




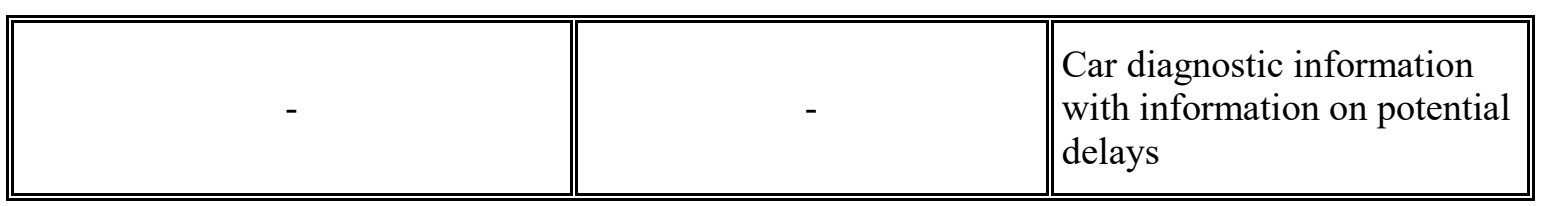

The project brings an increase in the predictability of trucks arrival to the port, adding the vehicular diagnosis data. This implementation will bring various logistic and reliability gains by port operator and the fleet manager, as shown in figure 12 .

In this figure the truck from JKL Company presents some problem diagnosed. In this case the fault level could be assessed to determine a potential delay of its cargo delivery. So its schedule would be automatically canceled without associated penalty and another delivery could have the scheduling in advance. It would also be possible to transfer the cargo from this truck to another, reducing the chances of a ship leaving without a load expected by the shipowner.

These data allow complete control of the process of cargo delivery.

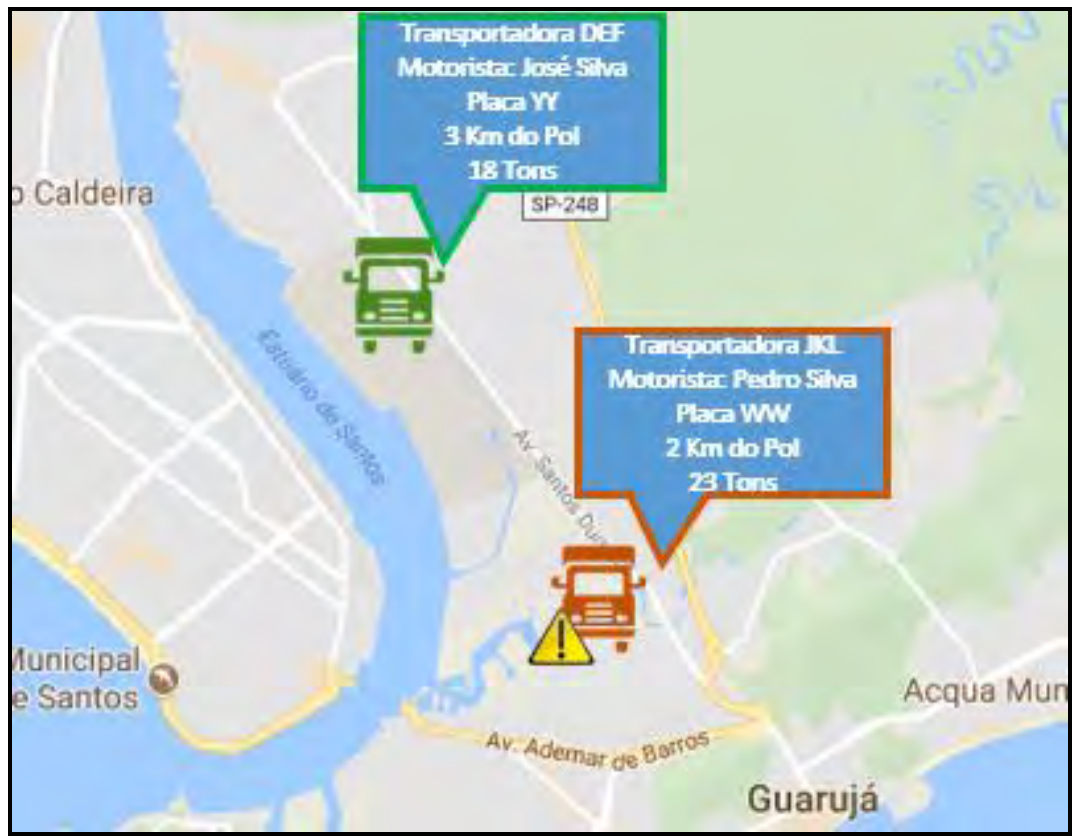

Figure 12. Expected overview after implementation of the Portotrack Project Phase 2.

\section{Conclusion}

Port logistics is highly complex due to the various agents involved, volume of cargo transported and the mens of transportation involved. In order to improve mainly the time arrival accomplishment of the trucks transporting the cargo, two project was created, The first one in 2012 (SGTC) and later in 2014 Portolog (Intelligent Port Logistics Chain). Part of the project was implemented with the creation of a truck scheduling system, Then it was planned additional steps including RFID identification, deployment of logistic warehouses and also the real-time tracking of truck. 
This article aimed to propose a project called Portotrack aiming the interconnection between the tracking data of the trucks and Portolog system. The project brings eanirgs in the predictability trucks arrival to the port, adding the data of vehicular diagnosis as to assist in this process. This implementation will bring several logistic gains by the operator and fleet manager.

\section{References}

[1] Secretaria dos Portos. [Online] [Acess on : July 2015] www.portosdobrasil.gov.br

[2] Porto de Santos. [Online] [Acess on : July 2015] http://www.portodesantos.com.br/estatisticas.php

[3] Site do governo Nacional [Online] [Acess on : July 2015] http://www.brasil.gov.br/infraestrutura/2014/02/campanha-orienta-sobre-agendamento-decargas-no-porto-de-santos

[4] Porto de Santos. [Online] [Acess on : ttp://www.portodesantos.com.br/pdf/RES-136-2013.pdf

[5] ABREU, Vander Serra de. "Desenvolvimento e implantação do BDCC - Banco de Dados Comum de Credenciamento para controle de acesso pela autoridade aduaneira no Porto de Santos.” Tese Mestrado. Universidade de São Paulo, 2016.

[6] Portos e Navios. [Online] [Acess on : August 2017] https://www.portosenavios.com.br/portos-e-logistica/23402-agendamento-online-tentaacabar-com-filas-no-porto-de-santos

[7] POVIA, Mário. "Portos Infraestrutura Logística". ANTAQ. Apresentação na Comissão de Fiscalizçaão Financeira e Controle na Câmara dos Deputados. 2014. [Online] [Acess on : July 2017] http://slideplayer.com.br/slide/3109387.

[8] CODESP [Online] [Acess on : July 2017]. www.codesp.com.br

[9] Congresso Internacional de Desemvolvimento Portuário. [Online] [Acess on : july 2017]. http://www.cidesport.com.br/sites/default/files/a52176.pdf]

[10] Portos do Brasil [Online] [Acess on : July 2017].http://www.portosdobrasil.gov.br/assuntos-1/inteligencia-logistica/portolog]

[11] Admnistração dos Portos de Paranaguá e Antonina. [Online] [Acess on : July 2017]. http://www.sistemas.appa.pr.gov.br/appa/seguranca/seglogin.asp

[12] FMS Standard. [Online] [Mrach 2017] http://www.fms-standard.com/. 